\title{
Capítulo 10 Uso del mezquite (Prosopis spp.) como recurso alimenticio
}

\section{Chapter 10 Use of mesquite (Prosopis spp.) as a food resource}

ALTAMIRANO-FORTOUL, Rossana del Carmen $\dagger^{*}$

Universidad de la Cañada, Instituto de Tecnología de los Alimentos

ID $1^{\mathrm{er}}$ Autor: Rossana del Carmen, Altamirano-Fortoul / ORC ID: 0000-0002-5323-8931, CVU CONACYT ID: 176818 DOI: $10.35429 /$ H.2020.9.130.147

R. Altamirano

rossana@unca.edu.mx

A. Marroquín, J. Olivares, L. Cruz y A. Bautista. (Coord) Biología. Handbooks-@ECORFAN-Mexico, Querétaro, 2020. 


\title{
Resumen
}

En los últimos años han surgido cambios relacionados con las costumbres alimenticias entre los cuales destaca el interés por los alimentos con cierto valor añadido como son los ricos en fibra dietética, ácidos grasos, probióticos, prebióticos, bajos en calorías, en grasas y con aditivos naturales que prolonguen su vida útil. En consecuencia, las investigaciones se han centrado en explorar diferentes alternativas para dar respuesta a dichas demandas. Sin embargo, el desarrollo de nuevos productos alimenticios es un constante desafío, el cual incluye como parte fundamental la optimización de los ingredientes para generar la mejor formulación. Además, se ha fortalecido el interés mundial en investigar cultivos subexplotados, ya no solo por el aspecto agronómico, sino por su valor nutritivo. Uno de estos cultivos es el mezquite, ya que dentro de sus usos tradicionales y antiguos se encuentra el empleo de sus vainas o frutos en la alimentación humana. Por lo tanto, en este capítulo se incide el interés por rescatar el uso de la vaina de mezquite como materia prima en productos alimenticios tales como los productos de panificación, lo anterior con el fin de aumentar el aporte de fibra, minerales, así como el contenido de proteína, sin afectar sus propiedades tecnológicas y sensoriales.

\section{Vaina de mezquite, Productos con valor añadido, Productos de panificación.}

\begin{abstract}
In recent years, changes have emerged in eating habits, including interest in foods with a certain added value, such as rich in dietary fibre, fatty acids, probiotics, prebiotics, reduced calories, low-fat foods, and foods with natural additives wich extende their shelf life. Consequently, the research has focused on explore different alternatives to meet these demands. However, the development of new food products is a constant challenge, which includes the optimization of the used ingredients as a fundamental step to develop the best formulation. In addition, there is a great world's interest to investigate the underexploited crops, not only due to the agronomic interest, but for their nutritional value. One of these crops is the mesquite, since its traditional and ancient uses includes the utilization of pods or fruits as human food. Therefore, this chapter review the interest to rescue the use of the mesquite pod as a raw material in food products such as bakery products in order to increase the fiber, minerals, and protein content, without modify their technological and sensory properties.
\end{abstract}

\section{Mesquite pods, Added value products, Bakery products.}

\section{Introducción}

México posee una diversidad de productos agrícolas con propiedades nutricionales excelentes, entre éstos se encuentra el mezquite; el cual se localiza en zonas áridas y semiáridas de México, siendo una de ellas la Cañada Oaxaqueña, es subutilizado, debido principalmente al desconocimiento de sus características químicas, físicas y funcionales ya que existe un gran número de especies de Prosopis que no han sido estudiadas desde el punto de vista funcional y nutricional.

El mezquite es científicamente conocido como Prosopis, pertenece a la familia Leguminosae, de la subfamilia Mimosoideae, que incluye aproximadamente 44 especies de mezquite, de las cuales 42 se encuentran localizadas en el continente americano (Felker, Takeoka y Dao, 2013). Siendo un recurso biótico, de él se obtienen varios productos entre los cuales se encuentran muebles, combustible y sus frutos o vainas que se emplean intensivamente como forraje para ganado, así como también es consumido como alimento por los habitantes de ciertas regiones donde prevalece este árbol. La vaina de mezquite, es de color amarillenta, marrón o negra (dependiendo de la especie) compuesta por: exocarpio, mesocarpio (pulpa), que juntos representan entre 55-58\% en peso del fruto, según la especie, endocarpio (30-35\% del fruto) y semillas (aproximadamente 10-14\%) (Grados y Cruz, 1996).

El uso de las vainas de mezquite en la alimentación humana es muy antiguo, tanto en América, como en Asia y África. Las vainas de mezquite son dulces por su alto contenido de sacarosa, así como ricas en fibra, proteínas y minerales; pese a estos beneficios aún no se ha desarrollado por completo una forma factible para transformar la materia prima y darle valor agregado; por ejemplo, las proteínas presentes en harina de las vainas tienen un comportamiento viscoelástico semejante al del gluten de trigo, lo cual podría aprovecharse para generar nuevos productos derivados de cereales. 
Pero en México existe escasa información acerca de la inclusión de las vainas de mezquite en formulaciones alimenticias con el fin de obtener productos que reúnan las características aceptables por los consumidores, además de aportar o reforzar nutrimentos que proporcionen un efecto benéfico a la salud de éstos.

Por lo tanto, el objetivo de este trabajo fue plasmar el uso del mezquite en productos alimenticios. Para esto se recopiló información referente al mezquite, así como la importancia de uno de sus productos principales, las vainas o frutos; las cuales son una alternativa para implementar en el desarrollo de nuevos productos alimenticios en nuestro país, ya que estas son consumidas en bebidas o platillos en países del Sur de América. Cabe señalar que en este capítulo además de identificar productos elaborados a partir de los frutos o vainas de mezquite en otros países, se hace mención del desarrollo de nuevos productos de panificación a partir de vainas de mezquite procedentes de la Región Cañada, Oaxaca.

En este capítulo se presentan algunos resultados obtenidos durante el desarrollo del proyecto "Evaluación del efecto de la adición de harina de vaina de mezquite (Prosopis laevigata) y diferentes aceites esenciales en productos derivados de cereales" aprobado y financiado por PRODEP en su convocatoria PRODEP-NPTC 2016. El proyecto fue desarrollado en el Taller de Alimentos y laboratorio de biología de la Universidad de la Cañada. El objetivo de dicho proyecto fue evaluar el efecto de la adición de harina de vaina de mezquite (Prosopis laevigata) y aceites esenciales en diferentes formulaciones de productos derivados de cereales.

Con la información expuesta en este capítulo se busca contribuir en el aprovechamiento de la vaina de mezquite para el desarrollo de nuevos productos alimenticios. Así mismo, los resultados obtenidos en los productos de panificación ayuden a conocer sobre cómo la inclusión de harina de vaina de mezquite influye sobre las propiedades tecnológicas, nutricionales, así como sensoriales en los productos finales; lo anterior con el propósito de potencializar su valor agregado.

\subsection{Generalidades del mezquite}

El mezquite, proveniente de la palabra azteca misquite y recibe diferentes nombres que dependen de la región en donde se localiza, algunos son úthu, chúcata y tiritzecua en Michoacán; mientras que en Colima, Jalisco y Nayarit se le conoce como algarrobo (Trejo, 2010). Es una especie botánica que pertenecen a la familia Leguminosae, subfamilia Mimosoideae, y genero Prosopis. México posee una amplia extensión de mezquite; de acuerdo a Palacios (2006), se estiman 11 especies de Prosopis en el territorio nacional, entre las que se encuentran $P$. ordorata, $P$. glandulosa, $P$. glandulosa var glandulosa, $P$. velutina, $P$. articulata, $P$. tamaulipana, $P$. yaquiana $s p$., $P$. vidaliana, $P$. laevigata y $P$. mezcalina $s p$.

El género Prosopis es una planta arbustiva silvestre que habita en las zonas áridas, semiáridas y subtropicales de diferentes partes del mundo. Sin embargo, su origen se ubica en África, donde persiste como una sola especie; Prosopis africana. En nuestro país, el mezquite se encuentre principalmente en el Norte, centro y en la vertiente del pacifico desde Michoacán hasta Oaxaca, ya que se presentan las condiciones necesarias para su desarrollo (Palacios, 2006); puesto que dicha planta se caracteriza por ser una de las más resistentes en las zonas secas debido a la capacidad de almacenamiento de agua, a sus raíces profundas y a la fijación de nitrógeno en el suelo. Esto último indica que produce sus propios compuestos debido a la simbiosis entre las bacterias fijadoras de nitrógeno y los nódulos que se desarrollan en sus raíces; lo cual da lugar a que no necesite fertilización con nitrógeno para un mejor crecimiento.

En general, el mezquite está constituido por la morfología que se describe a continuación (Valenzuela et al., 2015):

Raíz. - Es amplia y profunda, llegando a alcanzar más de 50 m y sus raíces laterales se extienden hasta $15 \mathrm{~m}$ a los lados del árbol.

Tronco y ramas. - El tronco presenta una corteza oscura, las ramas son flexuosas que forman una copa esférica con espinas axiales y tallos delgados, así como afilados y provistos de abundante parénquima cortical cumpliendo la labor de hojas atrofiadas. 
Hojas. - Son compuestas, biparipinnadas, estipulas subuladas, con glándulas sensibles que cuentan con 12 a 15 pares de foliolos oblangos o lineares, de 5 a $10 \mathrm{~mm}$ de largo; únicamente presenta un par de pinnas por hoja. La época de formación de renuevos se extiende desde marzo hasta mayo; los foliolos permanecen en la planta de abril a diciembre.

Flores. - Son de color amarillo verdoso, bisexuales y actinomorfas con 5 sépalos y 10 estambres, se encuentran agrupadas en racimos con forma de espiga; las flores son pequeñas, miden de 34 a $10 \mathrm{~mm}$ y están situadas sobre pedúnculos de 1 a $2 \mathrm{~mm}$, produciendo un aroma agradable (Rodríguez et al., 2014).

Fruto. - los frutos son vainas o legumbres en forma alargada, recta o arqueadas y en algunos casos; se desarrolla cuando la flor ha sido fecundada.

De acuerdo a la literatura, en el altiplano norte-centro y en partes de Morelos, Puebla, Tamaulipas, Chiapas y Oaxaca, la especie que predomina es Prosopis laevigata; la cual es una planta leñosa que se visualiza como arbusto midiendo entre 2 y $3 \mathrm{~m}$; no obstante, puede crecer en forma de árbol teniendo una altura de 6 a $14 \mathrm{~m}$. Estudios realizados por Ortiz (2019) en árboles de mezquite localizados en Teotitlán de Flores Magón, Oaxaca (Región Cañada); presentaron las siguientes características:

Se pueden encontrar árboles o arbustos de 3.0-9.0 m de alto, sus hojas presentan estípulas de 2.5$4.0 \mathrm{~mm}$ de largo, subuladas, glabras, margen espaciadamente ciliado; pecíolos de 0.2-3.5 cm de largo, con una glándula cilíndrica; raquis a veces con glándulas cilíndricas; pinnas 1-2 pares; folíolos 15-30 pares por pinna de $0.5-1.2 \mathrm{~cm}$ largo y $1.0-3.0 \mathrm{~mm}$ de ancho; lineares u oblongos, base oblicua, ápice agudo u obtuso, glabros o puberulentos en ambas superficies; generalmente glaucos, nervaduras reticuladas prominentes en el envés, margen espaciadamente ciliado o liso, subcoriáceos. También cuentan con racimos que pueden contener de 150-300 flores de 5.0-13.0 cm largo, solitarios o en fascículos de 2-4; pedúnculos de 0.5-2.0 cm largo, brácteas del pedúnculo entre 1-2, así como 1.0-3.0 $\mathrm{mm}$ de largo; cuculiformes a lanceoladas, brácteas florales de $0.5-0.7 \mathrm{~mm}$ de largo, espatuladas a cuculiformes, glabras a pubescentes. Las flores con pedicelos entre 0.5-1.0 mm largo, glabros a pubescentes; cáliz de 0.6-1.0 mm largo, campanulado, margen ciliado o liso; corola de 2.5-4.0 mm de largo, con 5 pétalos linear-lanceolados, amarillos a blanco-verdosos o blanco-amarillentos; superficie externa glabra a puberulenta, superficie interna lanosa, fusionados hasta la mitad de su longitud o libres en la antesis; cuenta con 10 estambres, filamentos libres, blancos; ovario glabro o lanoso, estilo velloso y estigma truncado (Figura 10.1).

Figura 10.1 Flor de Prosopis laegivata

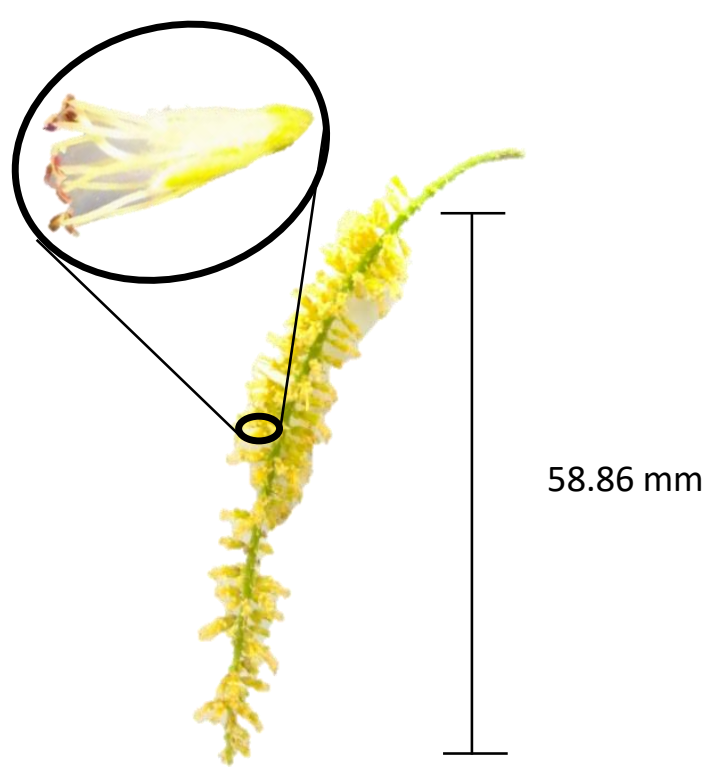

Fuente de Consulta: Ortiz (2019) 
En el caso de los frutos o vainas conocidas como legumbres se encuentran de 1-6 por racimo, entre 6.0-21.0 cm de largo y 7.0-11.0 mm de ancho, son rectas o ligeramente curvadas, comprimidas o no entre las semillas; presentan exocarpio estriado, glabro o puberulento; estas vainas pueden ser de color amarillo a rojizo, contando con semillas de 10-20 por vaina, insertadas oblicua a transversalmente en el fruto y son lenticulares (Figura 10.2 A). Además, tienen ramas con espinas caulinares, rectas de 0.5-9.0 $\mathrm{cm}$ de largo y laterales a las estípulas (Figura 10.2 B y C).

Figura 10.2 Frutos o vainas de Prosopis laegivata

\section{A}

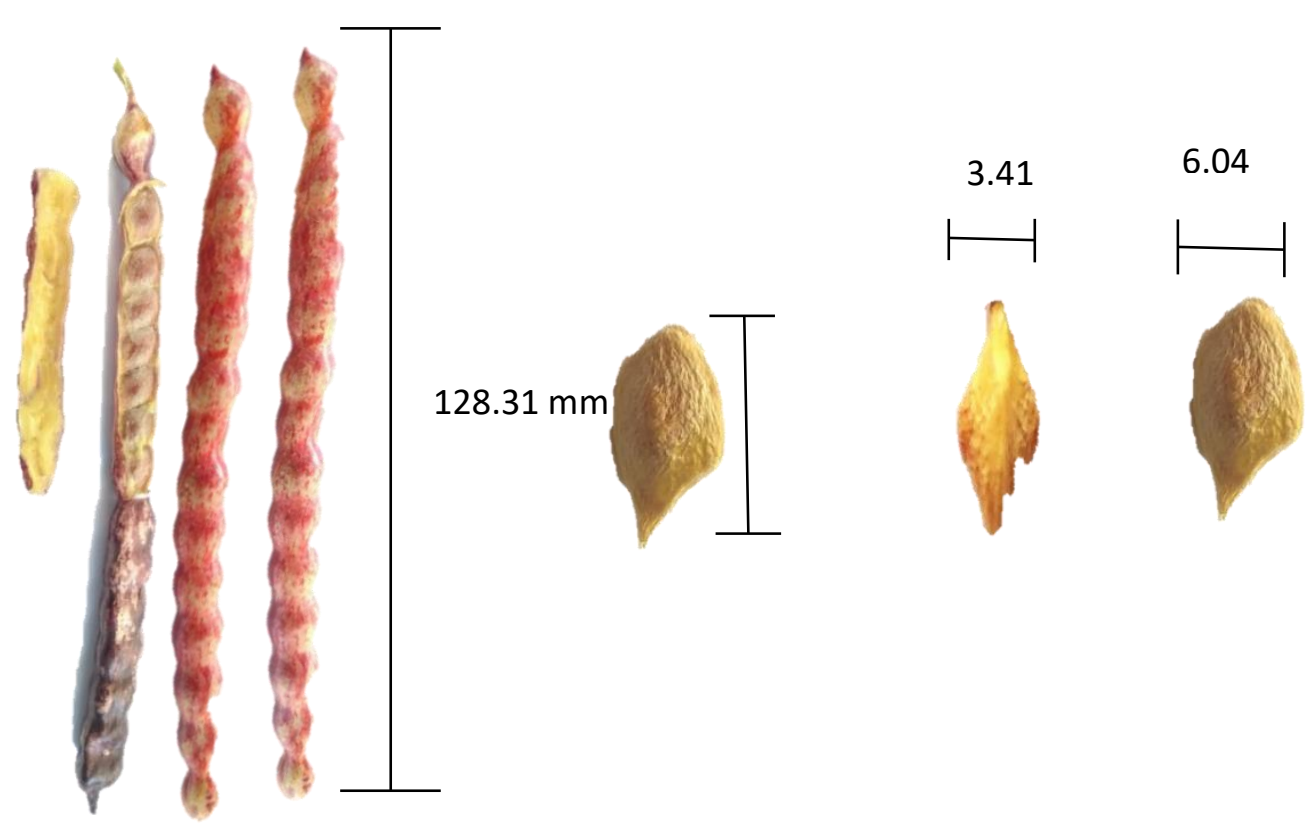

$\mathrm{C}$

B

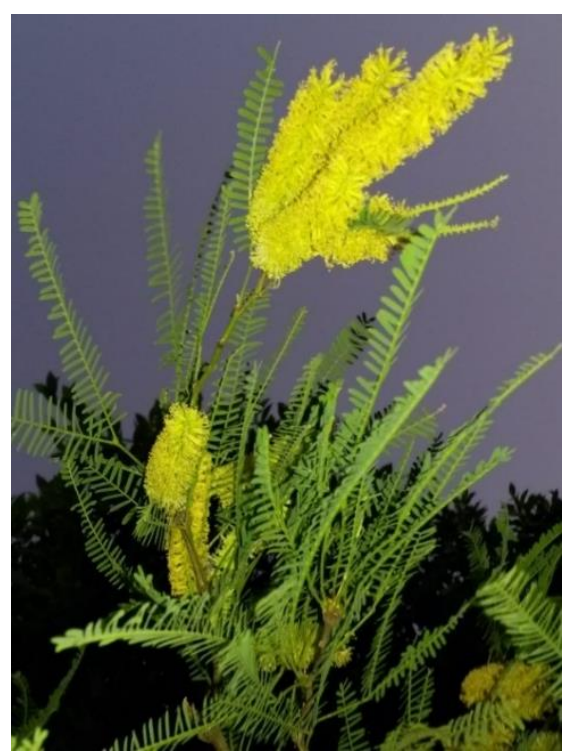

Frutos o vainas (A), Espinas (B) y Rama floreando (C)

Fuente de Consulta: Ortiz (2019)

Por otra parte, a pesar de que algunas especies de mezquite son consideradas como mala hierba, la mayoría de éstas han sido usadas para mejorar el ecosistema, así como en diferentes áreas, tal y como se presenta en la Tabla 10.1, en donde se especifica el uso y aprovechamiento de cada parte del mezquite. Como se observa, el mezquite tiene diversos usos, desde medicina debido a sus funciones antiséptica, propiedades antibacterianas y antivirales; hasta en la elaboración de muebles con su madera o la obtención de harina a través de la molienda de su fruto o vaina. 
Tabla 10.1 Usos y aprovechamiento del mezquite

\begin{tabular}{|c|c|c|c|c|}
\hline Parte apreciable & Alimentación humana & Medicina & Forrajero & Forestal \\
\hline Corteza & & $\begin{array}{l}\text { Antidisentérico y } \\
\text { gastritis. Infusión de } \\
\text { trozos de corteza. }\end{array}$ & & $\begin{array}{l}\text { Curtiduría. } \\
\text { Corteza del } \\
\text { mezquite. }\end{array}$ \\
\hline Ramas y tronco & & $\begin{array}{l}\text { Desinflamatorio. } \\
\text { Pomada de ceniza de } \\
\text { leña con manteca }\end{array}$ & & $\begin{array}{l}\text { Arados, } \\
\text { construcción de } \\
\text { viviendas, vigas, } \\
\text { elaboración de } \\
\text { artesanías, } \\
\text { refugio de vida } \\
\text { silvestres. }\end{array}$ \\
\hline Hojas & & $\begin{array}{l}\text { Antiséptico. Lavado } \\
\text { de los ojos con } \\
\text { infusión a partir de las } \\
\text { hojas. }\end{array}$ & $\begin{array}{l}\text { Ramoneo de follaje } \\
\text { verde o seco. } \\
\text { Ganado bovino, } \\
\text { caprino, ovino, } \\
\text { caballar, mular, } \\
\text { asnal y porcino. }\end{array}$ & \\
\hline Flor & $\begin{array}{l}\text { Miel (generada por las } \\
\text { abejas que chupan el } \\
\text { néctar de la flor). }\end{array}$ & & & \\
\hline Vaina & $\begin{array}{l}\text { Fruta fresca, fruta en } \\
\text { almíbar, pinole, queso de } \\
\text { mezquite (alimento } \\
\text { básico de los } \\
\text { chichimecas), piloncillo, } \\
\text { atole, vino. }\end{array}$ & & $\begin{array}{l}\text { Consumo de vainas } \\
\text { y harinas. }\end{array}$ & \\
\hline Goma & $\begin{array}{l}\text { Goma } \\
\text { niños. }\end{array}$ & $\begin{array}{llr}\text { Laringitis. } & \text { La } & \text { goma } \\
\text { disuelta } & \text { para } & \text { la } \\
\text { infusión. } & & \\
\end{array}$ & & $\begin{array}{l}\text { Pólvora de } \\
\text { escasa potencia. }\end{array}$ \\
\hline
\end{tabular}

Fuente de Consulta: Cervantes (2002)

\subsection{Vaina de mezquite}

Como se mencionó, el mezquite produce frutos, a los cuales se les denomina vainas, éstas son de color amarillo pálido, café o negro dependiendo de la especie; con forma de fruta dehiscente carnosa alargada levemente curveadas que contiene entre 12 a 20 semillas. La vaina puede llegar a medir 10 a $25 \mathrm{~cm}$ de largo, de $1.5 \mathrm{~cm}$ de ancho y $0.8 \mathrm{~cm}$ de espesor, con un peso promedio de $12 \mathrm{~g}$; la cual está conformada por tres partes principales (Figura 10.3): mesocarpio constituye 58\%, endocarpio 35\% y semilla $14 \%$. La semilla es lenticular, comprimida, su color varía de café claro a oscuro en base a la especie, variedad y sitio donde se produce (Grados y Cruz, 1996; Sciammaro, Ferrero y Puppo, 2016). La productividad de la vaina depende de la edad del árbol y la calidad del suelo; por ejemplo, los árboles viejos llegan a producir hasta $100 \mathrm{~kg}$ de vainas al año, mientras que los árboles adultos presentan una producción entre $40 \mathrm{~kg}$ por año. 
Figura 10.3 Estructura de la vaina de Prosopis spp.

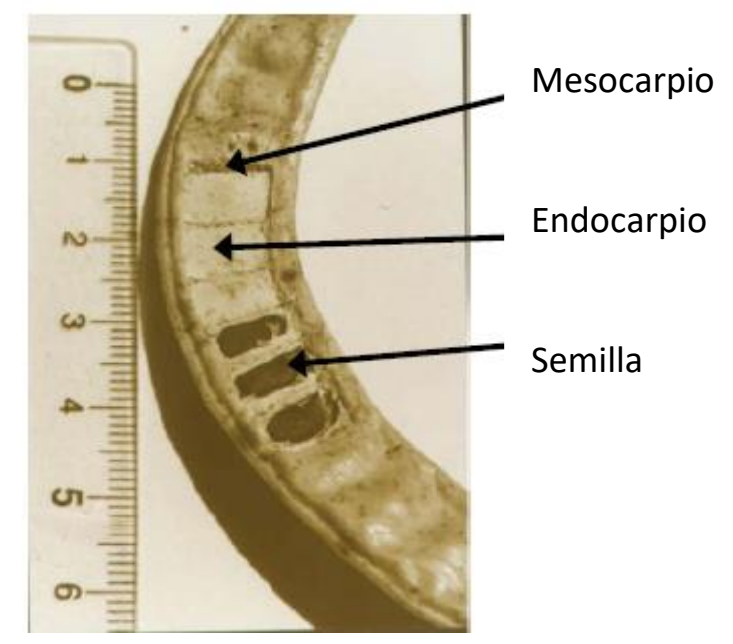

Fuente de Consulta: Adaptado de Felker (2013)

Debido a que el mezquite es una planta silvestre, se tiene mayor acceso a éste para la recolección de las vainas, las cuales se recogen manualmente y posteriormente son almacenadas para evitar que insectos como Bruchidae y Pyralidae las infesten. El procesamiento de los frutos de Prosopis spp. dependerá del producto que se desee obtener, ya sea utilizando la totalidad de la vaina o alguna de las fracciones (exocarpio, mesocarpio, endocarpio o semillas). Cada uno de estos componentes puede tener aplicaciones industriales en la elaboración de alimentos.

Por otra parte, varios autores han estudiado vainas de especies de mezquite originadas en regiones geográficamente diferentes, lo anterior con el propósito de evaluar sus propiedades nutricionales. Sin embargo, la interpretación de los resultados es difícil, debido a que en algunos casos denominan vaina a la fruta entera, pero en otros se refiere al pericarpio (vaina sin semillas). Aunado a esto, se ha reportado que existe una variación significativa en los valores nutricionales entre especies e incluso entre plantas de la misma especie. No obstante, en general las vainas contienen de $7-22 \%$ de proteína, 30-75\% de carbohidratos, cantidades aceptables de minerales ( 3 a 6\%), 2.8\% grasas, 11 a 35\% de fibra cruda y un perfil completo de aminoácidos (Barba de la Rosa et al., 2006; Altamirano-Fortoul 2018; Ruiz, 2011). Además, la composición aminoacídica de sus proteínas deja ver la presencia de importantes cantidades de aminoácidos esenciales, destacando el contenido relativamente alto de lisina; lo cual convertirían a las vainas de mezquite en un excelente complemento de otras proteínas deficientes en este aminoácido, como es el caso de los cereales.

En la Tabla 10.2 se muestra una comparación de nutrientes presentes en diferentes variedades de Prosopis. En donde Felker et al. (2013) informaron para P. alba un contenido proteico de $7.17 \%$. Prokopiuk et al. (2000) destaca un contenido de azúcar (principalmente sacarosa) mayor al $30 \%$ en la fracción del mesocarpio de las vainas. Debido a esto, las harinas obtenidas de las vainas son dulces por su alto contenido de sacarosa constituyendo un alimento que aporta energía. Además, varios autores han estudiado la especie de $P$. pallida encontrando rangos para la proteína de $8.11 \%$, fibra $3.4 \%$, grasa $0.77 \%$. De igual forma, las vainas de Prosopis spp. contienen, entre otros minerales, potasio, calcio y magnesio. Además de su aporte nutricional debe destacarse el alto contenido de fibra dietética (principalmente fibra insoluble), así como su composición aminoacídica de las proteínas deja ver la presencia de importantes cantidades de aminoácidos esenciales, excepto (según la especie) de metionina, isoleucina y treonina (Ortiz 2019). Por otro lado, en el estudio realizado en árboles de P. laevigata, ubicados en la Cañada Oaxaqueña, específicamente en Teotitlán de Flores Magón, Oaxaca, se encontró que las vainas presentaron un alto contenido de humedad, grasa, ceniza y carbohidratos, al compararlo con los resultados para otros Prosopis descritos (Felker et al., 2013; Prokopiuk 2004; Barba de la Rosa et al., 2006; Ruiz, 2011; González-Barrón et al., 2020). No obstante, cabe señalar que los valores obtenidos en este estudio, presentan diferencias; lo anterior debido a las variedades de Prosopis, al estado de madurez de la vaina (vaina verde, vaina madura y vaina seca), el tratamiento aplicado a la vaina previo al secado, así como la fracción de la vaina (mesocarpio, endocarpio, pericarpio y semilla) utilizada para el estudio. 
Tabla 10.2 Principales nutrientes en las vainas procedentes de Prosopis alba, P. glandulosa, P. velutina, $P$. pallida y $P$. laevigata

\begin{tabular}{|c|c|c|c|c|c|c|c|}
\hline $\begin{array}{c}\text { Contenido } \\
(\mathrm{g} / 100 \mathrm{~g})\end{array}$ & $\begin{array}{c}\text { P.pallid } \\
\boldsymbol{a}^{A}\end{array}$ & P.pallida ${ }^{B}$ & $\underset{B}{P . a l b a}$ & P.alba ${ }^{C}$ & $\begin{array}{c}\text { P.velutina } \\
D\end{array}$ & $\begin{array}{c}\text { P.glandulos } \\
a^{E}\end{array}$ & P.laevigata $^{F}$ \\
\hline $\begin{array}{l}\text { Contenido de } \\
\text { humedad }\end{array}$ & ---- & 3.39 & 2.57 & 7.17 & ---- & 8.53 & 15.05 \\
\hline Proteína & 8.11 & 8.11 & 7.17 & 7.03 & 9.5 & 6.81 & 7.05 \\
\hline Grasa & 0.77 & 0.77 & 2.17 & 0.71 & 2 & 2.79 & 5.26 \\
\hline Colesterol & ---- & ---- & ---- & & ---- & ---- & ---- \\
\hline Cenizas & ---- & 3.6 & 3.13 & 2.58 & 4.5 & 3.44 & 6.06 \\
\hline Fibra & ---- & ---- & ---- & & 16 & 26.57 & \\
\hline Fibra cruda & ---- & 3.4 & 2.43 & 2.07 & ---- & & 4.52 \\
\hline Sacarosa & 46.35 & ---- & $\begin{array}{ll}--- \\
\end{array}$ & 38.2 & ---- & 27.02 & \\
\hline $\begin{array}{l}\text { Azucares } \\
\text { totales }\end{array}$ & ---- & 48.5 & 59.1 & & 48 & 31.6 & 62.06 \\
\hline Taninos & ---- & 0.41 & 0.57 & 0.583 & ---- & --- & --- \\
\hline Minerales & ---- & ---- & ---- & ---- & ---- & ---- & ---- \\
\hline $\mathrm{mg} / 100 \mathrm{~g}$ & ---- & ---- & ---- & ---- & ---- & ---- & ---- \\
\hline Calcio & 75.9 & 76 & 127 & 200 & ---- & 420 & --- \\
\hline Fosforo & ---- & ---- & --- & 140 & ---- & ---- & ---- \\
\hline Potasio & 2650 & ---- & ---- & 360 & ---- & 1030 & ---- \\
\hline Sodio & 113 & ---- & --- & 136 & ---- & 80 & ---- \\
\hline Magnesio & 90.4 & ---- & ---- & 81 & ---- & 60 & ---- \\
\hline
\end{tabular}

Fuente de Consulta: ${ }^{A}$ Grados y Cruz (1996); ${ }^{B}$ Felker y col. (2003); ${ }^{C}$ Prokopiuk (2004); ${ }^{D}$ Meyer (1984); ${ }^{E}$ Becker y Grosjean (1980); ${ }^{F}$ Ortiz ( 2019)

De acuerdo a lo anterior, debido al alto valor nutritivo presente en la vaina de mezquite, es común el uso de ésta como parte de la dieta del ganado. Además, su consumo reduce el costo de las raciones alimenticias que son proporcionadas al ganado bovino lechero y principalmente al de engorda, al igual que al porcino y caprino y con menor intensidad al caballar, asnal y mular (Arnero, 2015). Sin embargo, el uso de la vaina en la alimentación humana es de los elementos menos estudiados, en la Tabla 10.3 se presentan las posibles aplicaciones de la vaina de mezquite, en donde se hace referencia a la separación de la vaina en tres fracciones para la posterior obtención de varios productos.

Tabla 10.3 Posibles utilizaciones de la vaina de mezquite

\begin{tabular}{|l|l|}
\hline \multicolumn{2}{|c|}{ Parte de la vaina } \\
\hline Exo y Mesocarpio & $\begin{array}{l}\text { Sucedáneo de café } \\
\text { Sucedáneo de cacao } \\
\text { Jarabe de algarroba } \\
\text { Aditivo para comidas dietéticas }\end{array}$ \\
\hline Endocarpio & Aditivo para comidas \\
\hline $\begin{array}{l}\text { Semillas } \\
\text { Cotiledón } \\
\text { Endospermo }\end{array}$ & $\begin{array}{l}\text { Concentrado proteico } \\
\text { Goma }\end{array}$ \\
\hline
\end{tabular}

Fuente de Consulta: Grados y Cruz (1996)

\subsection{Uso e importancia de la vaina de mezquite en la alimentación humana}

La utilización de la vaina de mezquite como alimento humano es muy antiguo, tanto en Asia, África, así como en América (principalmente Perú, Chile y Argentina), siendo en estos países en donde se le conoce como vainas de algarrobo o algarroba. No obstante, en México, los primeros registros arqueológicos (6500 a.C) se encuentran en el Valle de Tehuacán, en donde se hallaron vainas de mezquite masticadas (Smith, 1967); así mismo hay evidencias de que los indios cazadores Chichimecas cosechaban las vainas de los mezquites para consumirlas como fruta seca o elaboraban una solución a partir del jugo de ésta. Además, las vainas jugaron un papel importante en el desierto de Sonora, ya que las tribus elaboraban harina y masa con la pulpa seca o tostada de las vainas maduras. 
Por lo tanto, el uso de vainas de mezquite para consumo humano data de hace mucho tiempo. Sin embargo, su uso en México se ha reducido significativamente, ya que solo las personas mayores de algunos pueblos siguen conservando las costumbres de sus ancestros para elaborar productos como bebidas, piloncillo, pan y atole a partir de vaina de mezquite.

Por otra parte, como se mencionó anteriormente, el mezquite pertenece a la familia de las leguminosas. La importancia alimenticia de éstas, radica en su alto contenido en proteínas, así como su conveniente proporción de grasas, su contenido de carbohidratos y minerales, lo cual ha propiciado su uso como alimento a lo largo de los siglos. Sin embargo, las legumbres presentan factores no nutritivos, cuya eliminación es ineludible si se las quiere usar como alimento. La mayoría de estas sustancias se eliminan mediante el remojo y la cocción, permitiendo que la utilización de las legumbres como parte de la dieta humada se haya preservando. Además de su elevada calidad nutricional, se ha demostrado que las leguminosas protegen frente a ciertas enfermedades como problemas cardiovasculares, diabetes, obesidad y cáncer.

De acuerdo a lo anterior, es importante conocer algunos productos obtenidos a partir de las vainas de mezquite con el fin recuperar su uso y aplicación en productos alimenticios o en el desarrollo de nuevos productos.

\subsection{Harina}

La harina de mezquite es un polvo fino que se obtiene de la molienda y tamizado de las vainas; para esto se utilizan tamices que proporcionen un producto con un tamaño de partícula fina (Figura 10.4). En México no se presenta una norma que defina a la harina procedente de la vaina de mezquite; no obstante, en el Art. 681 tris del Código Alimentario Argentino (2010) se define a la harina de fruto de algarrobo como el producto de la molienda de los frutos completos limpios, sanos y secos, del algarrobo blanco (Prosopis alba Griseb) y/o algarrobo negro [Prosopis nigra (Grisebach) Hieronymus].

Figura 10.4 Harina de vaina de Prosopis leavigata

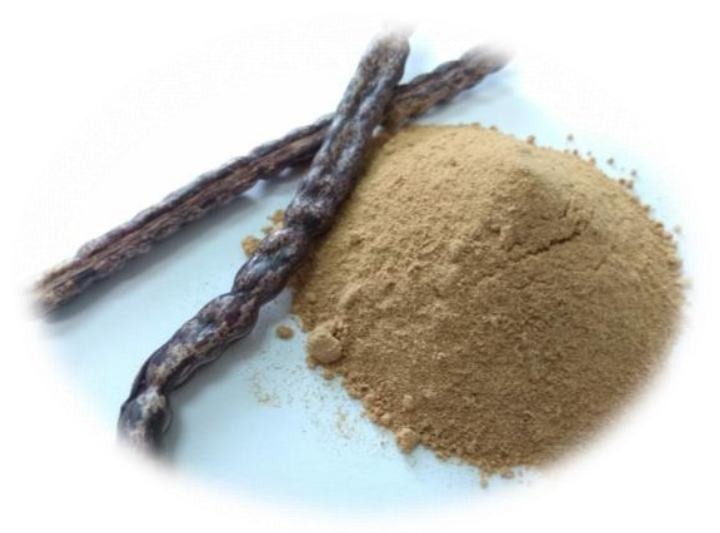

Fuente de Consulta: Ortiz (2019)

Para la obtención de harina se consideran principalmente las siguientes etapas: selección, lavado, escurrido, secado, molienda, tamizado y envasado. Los equipos básicos para llevar a cabo la obtención de la harina están conformados por lavadora de vainas, secador estático de bandejas, molino de martillos y tamizador. De acuerdo a Ortiz (2019) el rendimiento en harina respecto a materia prima es de 42\%; sin embargo, éste depende de la especie, así como de las etapas que se emplearon para la obtención de la harina. Por otro lado, en Perú existen varias unidades procesadoras semiindustriales que se dedican a procesar vainas de mezquite o algarrobo para obtener harina.

Por su parte, en Brasil, existen instalaciones para el secado y molido de algarrobas de la especie $P$. juliblora; el proceso incluye el secado de las algarrobas con un secador a leña en grandes recipientes abiertos, la temperatura empleada es de aproximadamente $80^{\circ} \mathrm{C}$ durante $4 \mathrm{~h}$. Posteriormente las algarrobas pasan a un molino de martillos con cribas de varios tamaños (Pasiecznik et al., 2001). 
No obstante, existen variantes acerca de la metodología para la obtención de la harina. Un ejemplo que presenta las etapas para obtener la harina de mezquite se muestra en la Figura 10.5, en donde se observa que éstas son similares a las reportadas por los autores citados anteriormente. Sin embargo, en algunos casos se aplica un tratamiento a la vaina previo a la molienda, con el propósito de eliminar los factores no nutritivos presentes en esta.

Independientemente de la forma en cómo se obtenga la harina de la vaina de mezquite, una vez conseguida ésta, se puede mezclar con otros alimentos para obtener bebidas, o para la preparación de postres, pastas, pasteles, entre otros (Barba de la Rosa et al., 2006; Bigne, Puppo y Ferrero, 2018).

Figura 10.5 Diagrama de flujo para la obtención de harina de vaina de mezquite (Prosopis laevigata)

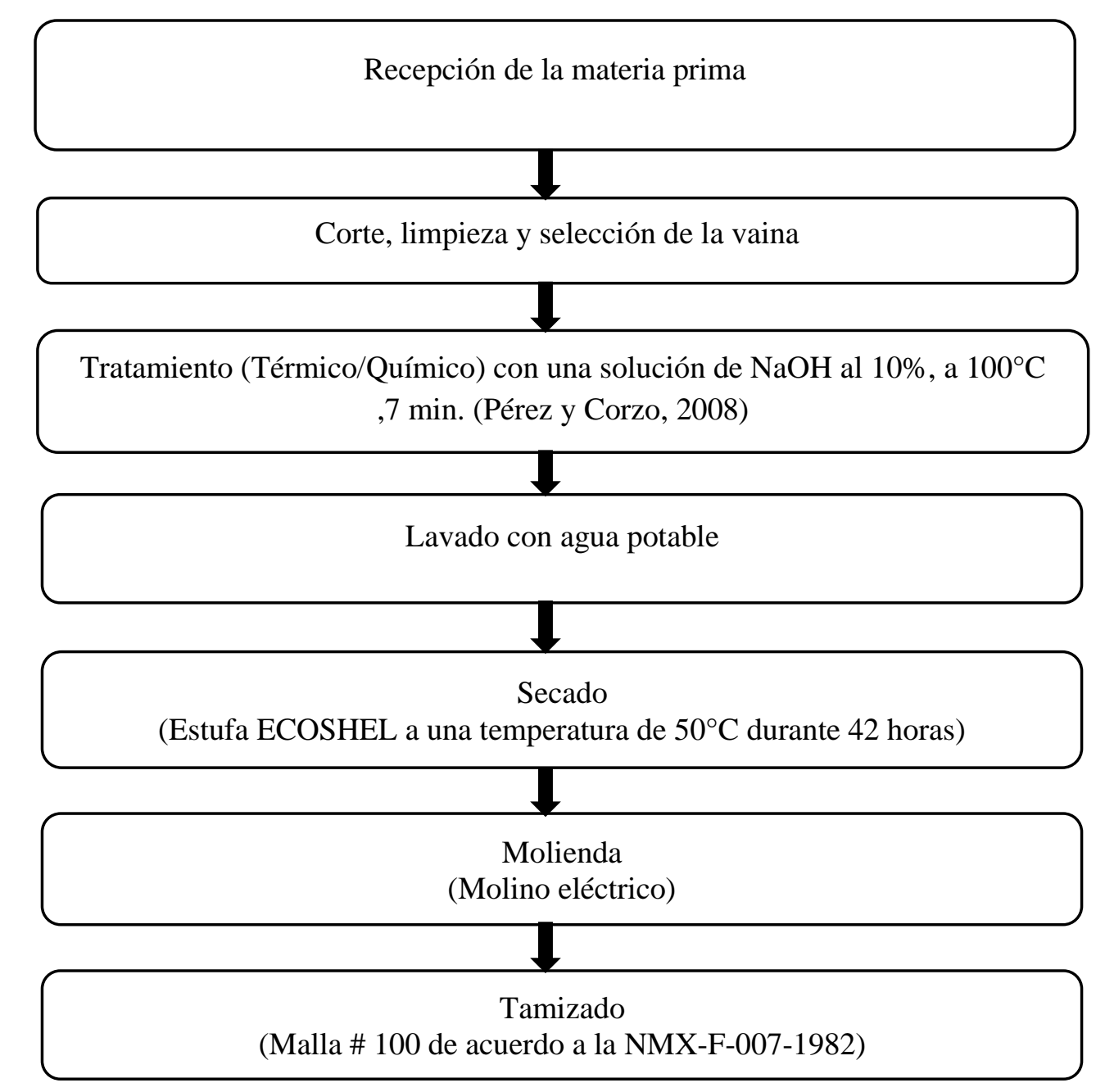

Fuente de Consulta: Elaboración Propia

\subsection{Bebidas}

En algunos países del sur de América, como es el caso de Perú, Argentina y Brasil, se consumen bebidas y jarabes obtenidos de la algarroba (vaina de ciertas especies de Prosopis), algunos de éstos se describirán en los siguientes párrafos.

La algarrobina es un jarabe concentrado de los azúcares naturales que se obtienen de la vaina de algarroba de 75 a $78^{\circ}$ Brix. En general, se elabora hirviendo el fruto con agua y luego se evapora hasta obtener un líquido espeso de color café obscuro brillante. La algarrobina pude ser utilizada de diferentes formas; se toma como tónico fortificante, así mismo, como saborizante, en ensaladas, leche, yogurt, así como para sazonar carnes y elaboración de dulces de leche. Para la producción de algarrobina las etapas consisten en: recolección con el propósito de disponer de materia prima todo el año; posteriormente se continúa con una selección manual de las vainas para separar las picadas y muy dañadas, después se almacenan las vainas sometiéndose a un proceso de pre-secado con el fin de disminuir su humedad. A continuación, se lavan las vainas para eliminar sustancias adheridas a éstas; se sigue con un troceado en un molino troceador para hacer más eficiente la extracción de azucares. 
Seguido de esto, se procede a una extracción de azúcares, en donde se mezcla las vainas de algarroba troceada con agua en una relación 1:4 (peso/volumen) y a continuación se hierven por dos horas, transcurrido este tiempo se separan las vainas cocidas (bagazo) y el jugo se hace pasar por una tela filtrante, el jugo contenido en el bagazo se separa por prensado y se adiciona al volumen obtenido inicialmente. Por último, se realiza una concentración con el jugo obtenido anteriormente hasta conseguir la algarrobina de 75 a $78^{\circ}$ Brix (Grados et al., 2000).

Por otra parte, también las vainas se han utilizado para preparar bebidas fermentadas; relatos antiguos indican que en Chile y Argentina desde hace siglos se elabora una bebida fermentada conocida como aloja; dicha bebida se obtiene a base de algarroba molida cocida en agua. De acuerdo a Guinnar (1947), los indios autóctonos elaboraban esta bebida a partir de la vaina madura, a la cual la trituraba con dos piedras, para posteriormente ponerla en una bolsa de cuero cubierta con agua y dejándola fermentar. No obstante, existen algunas variantes en la elaboración de la bebida, y dependiendo del lugar es su forma de consumo. Por ejemplo, en Tucumán, Argentina, su elaboración consiste en machacar con un mortero las vainas, y poner la pasta a fermentar con agua en una tina durante 24 horas; transcurrido el tiempo se sacan los restos de vainas que quedan y agregan mayor cantidad de vainas machacadas con el propósito que siga el proceso de fermentación. La proporción es vaina molida, 1 parte y agua 4 partes; cabe mencionar que la fermentación se propicia gracias al alto contenido de azucares presentes en la vaina.

Otra bebida a base de algarrobo, fue reportada en el estudio realizado por Cerezal et al. (2012), en el cual se desarrolló una bebida de alto contenido proteico a partir de algarrobo, lupino y quinoa para la dieta de preescolares. El algarrobo utilizado fue de la especie (Prosopis chilensis (Mol.) Stunz). Reportándose que, al concluir 90 días de almacenamiento, la bebida obtuvo un contenido de proteínas de $1.36 \%$, siendo el triptófano el aminoácido limitante; la tonalidad de la bebida fue rosado oscuro, la viscosidad y la evaluación sensorial resultaron aceptables.

En México, los chichimecas procesaban las vainas de mezquite para elaborar mezquiatole, desafortunadamente la elaboración de este y otros productos a base de mezquite han ido disminuyendo con el transcurso del tiempo y sólo quedan como alimentos típicos de ciertas regiones; además de no contar con escritos que reporten su elaboración, sino que pasan de voz a voz. Por ejemplo, en Guanajuato se continúa consumiendo mezquiatole. En donde, la bebida se prepara como un atole con masa, piloncillo, canela y se le incorpora el extracto de las vainas cocidas de mezquite (Alonso, 2017).

\subsection{Otros productos}

\section{Sucedáneo de café}

Cabe mencionar que se entiende por sucedáneo, cualquier sustancia que sustituye a otra, es decir "sustituto". Por tanto, debido a que ciertas personas no pueden consumir la mayoría de productos por razones de salud o intolerancia, se ha optado por desarrollar productos que sustituyan a otro con la finalidad de atender las necesidades de los consumidores. Tal es el caso del uso de las vainas de mezquite como sucedáneo de cacao.

Así mismo, se elabora sucedáneo de café a partir de la algarroba de Prosopis alba Grise; para esto, se seleccionan las vainas, se limpian, posteriormente pasan por un secado a $60^{\circ} \mathrm{C}$ durante 60 horas. Transcurrido este tiempo, se tuestan las vainas; de acuerdo a estudios realizados por Prokopiuk (2004) las temperaturas de tostado de 160 y $175^{\circ} \mathrm{C}$ dan lugar a un tostado similar al del café; además que el tostado modifica el comportamiento de la adsorción del agua en la vaina, disminuyendo la tendencia a la humectación y la capacidad de retención de agua. Como siguiente paso se muelen las vainas tostadas en un molino de martillos, el polvo obtenido se tamiza usando mallas de $0.85,0.25$ y $0.15 \mathrm{~mm}$, y por último se envasa la muestra. En base a los estudios realizados por el mismo autor, se observó que el tostado a $160^{\circ} \mathrm{C}$ dio lugar a una infusión con aroma más semejante al del café y tuvo mayor aceptación por parte de los panelistas; por lo que, las vainas pueden utilizarse en la obtención de sustituto de café. De hecho, en Perú, Argentina y Europa se comercializan productos registrados de sucedáneos de café o café de algarroba presentando un resultado aceptable en el mercado. 


\section{Patay}

Básicamente, es una torta elaborada con harina de algarroba y agua que puede consumirse a modo de turrón. Este alimento fue fundamental para la dieta de los pueblos aborígenes de Argentina. Su elaboración consiste en secar las vainas aproximadamente una semana, después son molidas para obtener la harina, se mezcla la harina con agua para obtener una masa, en seguida se coloca la masa en un molde en forma de aro, dejándola secar para posteriormente ser consumida, en algunos casos se hornea. Sin embargo, existen diferentes recetas para su elaboración, las cuales dependen de la cultura del lugar donde se consuma (Avellaneda y Cubas, 2018).

\section{Condimentos}

En África y Asia, se usan las vainas de la especie Prosopis africanana con el propósito de elaborar condimentos. La proteína vegetal fermentada tiene alimentos potenciales utilizados como suplementos proteicos y como ingredientes funcionales en los alimentos fabricados. Conocido con el nombre de Okpeye es producido un condimento a partir de las semillas de las vainas de prosopis por el proceso de fermentación tradicional (Achi, 2005). Actualmente se vende en el mercado local de ciertas comunidades de estos países; sin embargo, existe escaso conocimiento acerca de sus propiedades nutricionales y funcionales.

\section{Pinole}

Es un producto de origen prehispánico elaborado especialmente a base de maíz. El pinole se define como una harina de cereales o leguminosas ya sea secas o tostadas, algunas veces endulzado y mezclado con cacao, canela o anís. Algunos grupos propios mexicanos como es el caso de los Lacandones, Nahuas o Tarahumaras lo incorporan dentro de su dieta básica. Aunque con el paso del tiempo los granos utilizados para su elaboración han ido cambiando; por ejemplo, puede usarse tanto amaranto como vainas de mezquite. En estudios realizados por Gallegos-Infante et al. (2013), se elaboró pinole con vainas de mezquite de la especie Prosopis laevigata con el objetivo de determinar el efecto de procesamiento (secado/tostado) sobre las características antioxidantes del pinole. Para esto, las vainas fueron secadas a diferentes temperaturas $\left(60,70\right.$ y $\left.80^{\circ} \mathrm{C}\right)$ y posteriormente fueron tostadas, al final de este paso, se limpiaron y se molieron en un molino de cuchillas, y por último se tamizaron. Para preparar el pinole se mezclaron las harinas obtenidas del mesocarpio y la semilla. De dicho estudio se obtuvo que la temperatura de $80^{\circ} \mathrm{C}$ dio lugar a la mayor disminución de inhibidores de tripsina y lectinas (factores no nutritivos presentes en las vainas); así como los extractos de pinole en general no influenciaron la capacidad de inhibir la oxidación de las lipoproteínas de baja densidad y demostrando que el pinole de mezquite es una fuente de alimento para el ser humano.

\subsection{Evaluación del efecto de la adición de harina de vaina de mezquite (Prosopis laevigata) y diferentes aceites esenciales en productos derivados de cereales}

México posee una diversidad de productos agrícolas con propiedades nutricionales excelentes, entre éstos se encuentra la vaina de mezquite. Como se ha mencionado, las vainas de mezquite son dulces por su alto contenido de sacarosa, así como ricas en fibra, proteínas y minerales; pese a estos beneficios aún no se ha desarrollado por completo una forma factible para transformar la materia prima y darle valor agregado. Además, como es sabido, los cereales son la principal fuente de energía en la dieta de las poblaciones, así como una fuente de proteínas y minerales; por consecuencia su volumen de consumo es alto. Lamentablemente, las proteínas de los cereales son de calidad regular, debido a que sus niveles de lisina, aminoácido esencial para los seres humanos, son bajos. De entre los cereales, el trigo es relevante, puesto que los productos derivados de éste han sido parte de la dieta desde muchos siglos atrás. La harina de trigo es la más usada en panificación, debido a que contiene las proteínas requeridas para formar un gluten con las características necesarias para elaborar pan. Sin embargo, dada su naturaleza de cereal, el trigo es deficiente en lisina, por lo que se han buscado opciones, tal como la sustitución parcial de harina de trigo por harinas no convencionales o combinación de harinas, como es el caso de leguminosas, con el propósito de mejorar el valor nutricional de los productos de trigo (Altamirano-Fortoul, 2018; Bigne et al., 2018; Ortiz, 2019). 
Por lo tanto, en el proyecto "Evaluación del efecto de la adición de harina de vaina de mezquite (Prosopis laevigata) y diferentes aceites esenciales en productos derivados de cereales", desarrollado en la Universidad de la Cañada; se estudiaron alternativas para aprovechar la harina obtenida de la vaina de mezquite, como lo fue en la inclusión de un porcentaje de esta harina en galletas de masa corta, así como en pan de sal y/o pan de dulce tipo concha, en una proporción que no afectó los atributos tanto técnicos como sensoriales. Lo anterior, con el objetivo de obtener productos que reúnan las características aceptables por el consumidor y siendo similares a sus productos homólogos (obtenidos de 100\% harina de trigo); así como una propuesta para reforzar nutrimentos y como una posible propuesta de elaborar productos con un efecto benéfico a la salud de los consumidores. Aunado a la inclusión de harina de vaina de mezquite, a los productos se les incorporaron aceites esenciales (orégano en el caso de pan de sal, naranja en el pan tipo concha y canela para el caso de galletas) como aditivos naturales para su conservación.

Para llevar a cabo lo anterior, se obtuvo la harina de vaina de mezquite siguiendo la metodología indicada en la Figura 10.5. Posteriormente con la ayuda de un diseño experimental de mezclas se elaboraron diferentes formulaciones (Tabla 10.4, 10.5 y 10.6) con el fin de ser evaluadas sensorialmente para seleccionar las formulaciones de mejor aceptación.

Tabla 10.4 Formulación de galleta de masa corta

\begin{tabular}{|c|c|c|c|c|c|c|c|c|c|}
\hline \multirow[t]{2}{*}{ Formulaciones } & \multicolumn{9}{|c|}{ Ingredientes } \\
\hline & $\begin{array}{c}\text { Harina de } \\
\text { trigo } \\
(\%)\end{array}$ & $\begin{array}{l}\text { Harina } \\
\text { mezquite } \\
\quad(\%)\end{array}$ & $\begin{array}{c}\text { Ac. } \\
\text { esencial } \\
\text { de canela } \\
(\%)\end{array}$ & $\begin{array}{c}\text { Grasa } \\
(\%)\end{array}$ & $\begin{array}{c}\text { Azúcar } \\
(\%)\end{array}$ & $\begin{array}{l}\text { Leche } \\
(\%)\end{array}$ & $\begin{array}{l}\text { Sal } \\
(\%)\end{array}$ & $\begin{array}{c}\text { Leudante } \\
(\%)\end{array}$ & $\begin{array}{c}\text { Agua } \\
(\%)\end{array}$ \\
\hline$F A$ & 92.493 & 7.4625 & 0.045 & 60 & 30 & 0.576 & 0.15 & 0.315 & 9 \\
\hline$F B$ & 97.493 & 2.4925 & 0.015 & 60 & 30 & 0.576 & 0.15 & 0.315 & 9 \\
\hline$F C$ & 90 & 9.94 & 0.06 & 60 & 30 & 0.576 & 0.15 & 0.315 & 9 \\
\hline$F D$ & 92.493 & 7.4925 & 0.015 & 60 & 30 & 0.576 & 0.15 & 0.315 & 9 \\
\hline$F E$ & 94.985 & 4.985 & 0.03 & 60 & 30 & 0.576 & 0.15 & 0.315 & 9 \\
\hline$F F$ & 97.463 & 2.4925 & 0.045 & 60 & 30 & 0.576 & 0.15 & 0.315 & 9 \\
\hline Control & 100 & 0 & 0 & 60 & 30 & 0.576 & 0.15 & 0.315 & 9 \\
\hline
\end{tabular}

Fuente de Consulta: Elaboración Propia

Tabla 10.5 Formulación de pan de sal

\begin{tabular}{|l|r|r|r|}
\hline Formulación & \multicolumn{1}{c}{$\begin{array}{c}\text { Harina de } \\
\text { trigo }\end{array}$} & \multicolumn{1}{c}{$\begin{array}{c}\text { Harina de } \\
\text { mezquite }\end{array}$} & \multicolumn{1}{c|}{$\begin{array}{c}\text { Aceite esencial } \\
\text { de orégano }\end{array}$} \\
\hline$F A$ & 93 & 6.955 & 0.045 \\
\hline$F B$ & 96.484 & 3.48875 & 0.0225 \\
\hline$F C$ & 94.744 & 5.22187 & 0.03375 \\
\hline$F D$ & 98.222 & 1.74437 & 0.003375 \\
\hline$F E$ & 98.244 & 1.74437 & 0.01125 \\
\hline$F F$ & 94.744 & 5.24437 & 0.01125 \\
\hline Control & 100 & 0 & 0 \\
\hline
\end{tabular}

Fuente de Consulta: Elaboración Propia

Tabla 10.6 Formulación de pan de dulce tipo concha

\begin{tabular}{|l|r|r|r|}
\hline Formulación & \multicolumn{1}{|c}{$\begin{array}{c}\text { Harina de } \\
\text { trigo }\end{array}$} & \multicolumn{1}{c|}{$\begin{array}{c}\text { Harina de } \\
\text { mezquite }\end{array}$} & \multicolumn{1}{c|}{$\begin{array}{c}\text { Aceite esencial } \\
\text { de naranja }\end{array}$} \\
\hline$F A$ & 92.485 & 7.485 & 0.03 \\
\hline$F B$ & 96.243 & 3.7425 & 0.015 \\
\hline$F C$ & 96.213 & 3.7425 & 0.045 \\
\hline$F D$ & 88.743 & 11.2425 & 0.015 \\
\hline$F E$ & 88.743 & 11.2125 & 0.045 \\
\hline$F F$ & 85 & 14.94 & 0.06 \\
\hline Control & 100 & 0 & 0 \\
\hline
\end{tabular}


Cabe señalar, que el análisis sensorial es una herramienta esencial para evaluar la apariencia, color, textura y sabor entre otros, siendo clave para la elección de un producto de ingesta diaria. Por ello, es de suma importancia la información aportada por el panel de catadores establecido. En este estudio se utilizó un método afectivo cuyo principal propósito fue evaluar las respuestas (preferencia o aceptación) de los consumidores en cada uno de los productos derivados de las formulaciones. De lo anterior se obtuvo que, en la galleta de masa corta, la formulación $\mathrm{C}$ presentó mejores puntuaciones y una diferencia significativa para todos los atributos evaluados, comparadas con las obtenidas con las otras formulaciones. En cuanto al pan de sal, la formulación de mayor aceptabilidad fue la E; mientras que para el pan tipo concha, la formulación que seleccionaron los panelistas fue la C. Una vez seleccionados los productos de cada variedad, éstos fueron caracterizados fisicoquímicamente, los resultados de reportan en la Tabla 10.7. De lo cual se obtuvo en cuanto a la galleta, que la inclusión de harina de vaina de mezquite no afectó el contenido de proteína, así como de extracto etéreo. No obstante, incrementó el contenido de cenizas y fibra, no siendo así el contenido de carbohidratos y humedad de esta. Así mismo, los parámetros de color fueron afectados por la incorporación de harina de vaina de mezquite dando lugar a una galleta más obscura que la galleta control. Aunado a esto, la incorporación de la harina de vaina de mezquite influyó en la dureza de la galleta, dando lugar a un producto que requiere de mayor fuerza para su rompimiento a diferencia de la galleta control. Cabe señalar, que el aceite esencial de canela no influyó en las propiedades antes mencionadas.

Tabla 10.7 Propiedades fisicoquímicas de productos elaborados con harina de mezquite (Prosopis laevigata)

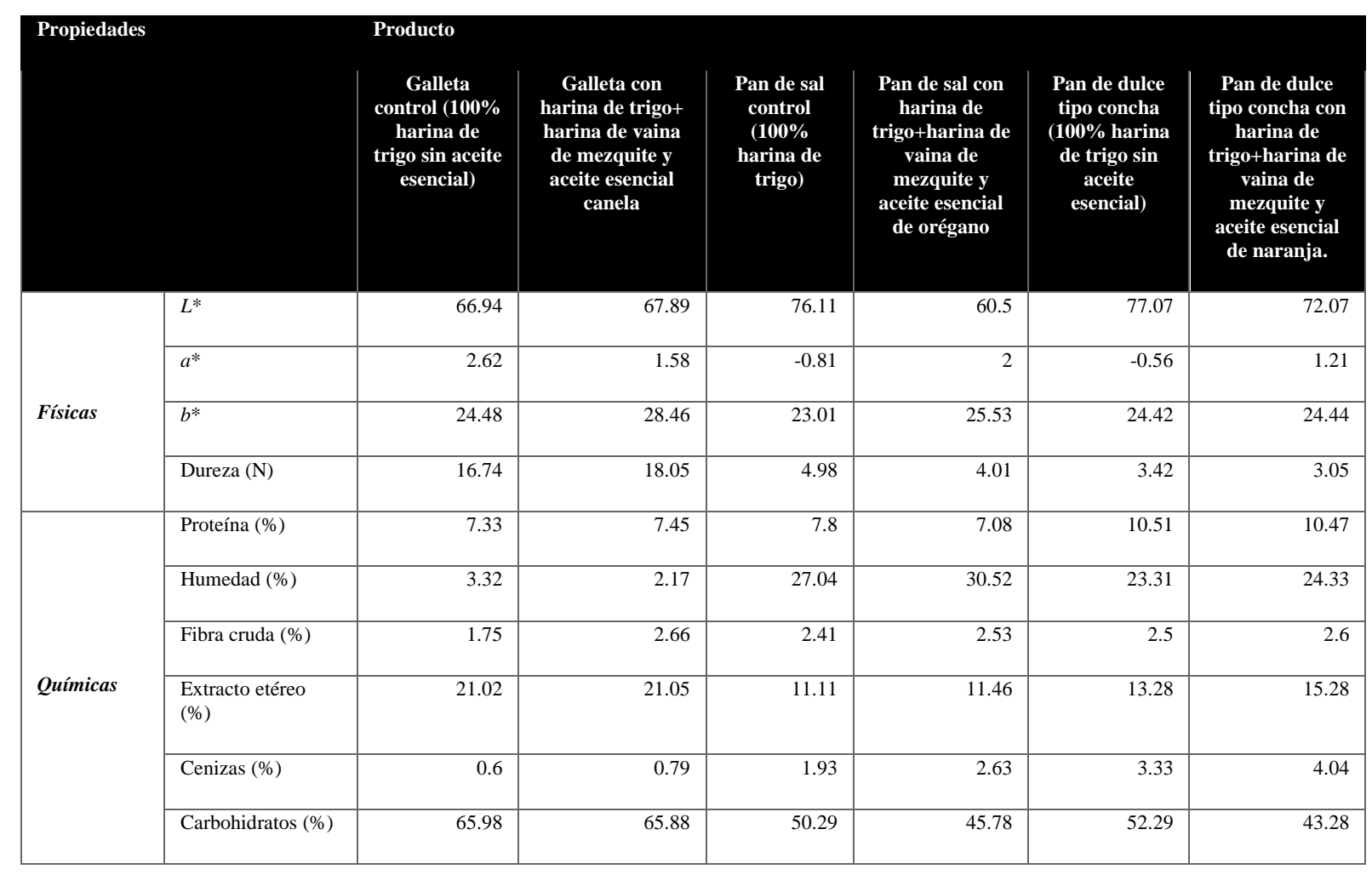

N: Newton; L: luminosidad; $a^{*}$ : la dirección del rojo (+) al tono verde (-), y $b^{*}$ indica el tono amarillo (+) y tono azul (-).

Fuente de Consulta: Elaboración

Con respecto al pan de sal, los resultados obtenidos en este estudio permitieron afirmar que la incorporación de harina de vaina de mezquite en la formulación, hacen posible obtener un producto con una diferencia en los macro y micro nutrientes respecto al pan control. Además, se observó un efecto en el color de la miga, en donde los parámetros de color indican que ésta fue más café; así mismo la incorporación de la harina de vaina de mezquite dio lugar a un pan con una dureza menor que el pan control. En cuanto al aceite esencial, este fungió como conservador natural, sin afectar las propiedades del producto. Por otra parte, en el pan de dulce tipo concha, la inclusión de la harina de vaina de mezquite, no modificó el contenido de proteína; no obstante, dio lugar a un incremento en cuanto al contenido de humedad, fibra, cenizas, extracto etéreo y carbohidratos. Al igual que en el pan de sal, el color de la miga fue más obscuro que el pan control y la dureza fue menor; así mismo la incorporación del aceite esencial, no influyó en las propiedades estudiadas. 
Como se observa, en general, el contenido de proteína en todos los productos que incluyen harina de vaina de mezquite presentaron una pequeña diferencia en los macro y micro nutrientes, con respecto a sus homólogos (100\% harina de trigo); sin embargo, se esperaba que los productos obtenidos con la inclusión de harina de vaina de mezquite presentaran un contenido de proteína mucho mayor que los controles. No obstante, es importante tener en cuenta que la calidad proteica está determinada por el contenido de aminoácidos esenciales; los cuales de acuerdo a lo reportado por Ortiz (2019), al comparar la harina de trigo con la harina de vaina de mezquite (Prosopis laevigata), son mayores en esta última en cuanto al contenido de Lisina, Valina y Leucina. Con respecto al contenido de fibra, se observó un ligero incremento de este en los productos con harina de vaina de mezquite; por lo que sería importante considerar que debido a que el trigo pierde parte de fibra durante la obtención de harinas blancas, la incorporación de harina de vaina de mezquite contribuiría a incrementar el contenido de fibra en los productos. Este dato también es reportado por otros autores, quienes afirman que la inclusión de harina de Prospis en la formulación de pan, aumenta el contenido de fibra en éste (Bigne, Puppo y Ferrero, 2016; Correa et al., 2017).

Así mismo el contenido de cenizas fue mayor en todos los productos con harina de vaina de mezquite, cabe señalar que las cenizas son el material inorgánico, como minerales, presentes en el alimento luego que se ha eliminado el agua y los materiales orgánicos como la grasa y la proteína, la harina que se usó para el presente estudio pertenece a la variedad Prosopis laevigata; en estudios previamente realizados se ha identificado a esta variedad con cantidades de cenizas mayor en relación con otras especies como la Prosopis alba en donde se reporta un contenido de 2 a $3 \%$. Mientras que en Prosopis nigra el contenido es de $2.14 \%$ (Prokopiuk et al., 2000).

Con respecto a los carbohidratos, los productos controles presentaron un mayor contenido en este macronutriente al compararlos con los obtenidos con harina de vaina de mezquite. Lo anterior puede deberse a que la determinación de los carbohidratos totales se ha llevado a cabo a partir de los resultados obtenidos del resto de componentes químicos, sus incrementos o reducciones se deben al comportamiento de dichos componentes. Sin embargo, cabe señalar que las leguminosas son fuente importante de carbohidratos complejos, algunos de absorción lenta como el almidón y otros no digeribles como los componentes de la fibra alimentaria.

Con respecto a la humedad presente en los panes, igualmente se observaron diferencias entre las muestras, presentándose mayor contenido de humedad en los panes con harina de vaina de mezquite; probablemente esto ocurre debido a la interacción de las macromoléculas presentes tanto en la harina de trigo como en la harina de vaina de mezquite, en donde se pudo haber reducido la concentración de humedad en el almidón, incrementando la retención de humedad en el gluten, logrando que se atara más agua a la miga. Se ha observado que al modificar las interacciones almidón-proteína en la matriz del pan, se originan cambios en el contenido de humedad tanto de la miga como de la corteza (Altamirano-Fortoul et al., 2012, Altamirano-Fortoul y Rosell, 2014).

En base a los resultados obtenidos en este proyecto; la sustitución parcial de harina de trigo por harina de vaina de mezquite (Prosopis laevigata) permitió elaborar productos de panificación de calidad aceptable, posiblemente con un contenido de aminoácidos más completos que los productos elaborados con $100 \%$ harina de trigo, dando lugar a productos con un valor añadido.

\subsection{Agradecimiento}

La autora del presente capítulo agradece a la Dra. María Eugenia Bárcenas Pozos, M.C. Jesús Manuel Campos Pastelín, así como a los ingenieros Luis Alfredo Ortiz Cid y Fabiola Jazmín Santiago Montero por su colaboración en el proyecto "Evaluación del efecto de la adición de harina de vaina de mezquite (Prosopis laevigata) y diferentes aceites esenciales en productos derivados de cereales". 


\subsection{Conclusiones}

Los árboles de mezquite se distribuyen en zonas áridas, semiáridas y subtropicales del mundo. México posee una amplia extensión de mezquite; estimándose once especies de este árbol en el territorio nacional. Del mezquite se obtienen varios productos entre los cuales se encuentran muebles, combustible y sus frutos o vainas se emplean intensivamente como forraje para ganado, así mismo es consumido como alimento en países del Sur de América.

Como se mencionó anteriormente, el mezquite tiene múltiples usos, interesándonos más en el área de alimentos, sus vainas o frutos se emplean intensivamente como fruta fresca, para la elaboración de pinole, jugo, bebidas fermentadas y condimentos. No obstante, en México se ha ido perdido el uso de las vainas o frutos del mezquite en la elaboración de alimentos. Además, existe información escasa del efecto de la inclusión de la harina obtenida de estas vainas en productos de panificación, surgiendo la duda si se obtienen productos con un alto contenido de proteínas, así como fibra; ya que se ha reportado que la sustitución parcial de harina de trigo por harinas de frutas o leguminosas, ha sido empleada para mejorar la composición química de panes sin afectar los atributos tecnológicos y sensoriales de éstos.

Aunado a lo anterior, el desarrollo de nuevos productos se enfatiza en proporcionar a los consumidores alimentos que provean un valor añadido. Por lo que, en la investigación: Evaluación del efecto de la adición de harina de vaina de mezquite (Prosopis laevigata) y diferentes aceites esenciales en productos derivados de cereales; la harina de vaina de mezquite, no presentó impedimento para la formación de la red de gluten en la masa, los productos elaborados fueron sensorialmente aceptables, además la incorporación de dicha harina presentó un efecto significativo en las propiedades físicoquímicas, permitiendo el incremento de algunos macro y micro nutrientes. Cabe señalar que la incorporación de los aceites esenciales dio lugar a la prolongación de la vida útil de los productos. Sin embargo, se recomienda seguir analizando la incorporación de diferentes concentraciones de harina de vaina de mezquite, de esta especie y de otras más, con la finalidad de mejorar el contenido nutricional y los parámetros tecnológicos de productos de panificación.

\subsection{Referencias}

Achi, O.K. (1992). Microorganisms associated with natural fermentation of prosopisAfricana seeds for the production of Okpiye. Plant Foods for Human Nutrition, 42, 97-304.

Alonso, J. (2017). Bebidas tradicionales y extravagantes de Guanajuato. Recuperado el 01 de julio de 2020:https://www.travelreport.mx/guanajuato/bebidas-tradicionales-de-mexico-guanajuatogastronomia/

Altamirano-Fortoul, R., Moreno-Terrazas, R., Quezada-Gallo, A., \& Rosell, C.M., (2012). Viability of some probiotic coatings in bread and its effect on the crust mechanical properties. Food Hydrocolloids, 29, 166-174.

Altamirano-Fortoul, R., \& Rosell, C.M. (2014). Influence of amyloglucosidase in bread crust properties. Food Science and Technology, 7(4), 1037-1046.

Altamirano-Fortoul, R., Campos-Pastelín, J.M., Bárcenas, P.M., \& Montero-Santiago, F. (2018). Efecto de la incorporación de harina de vaina de mezquite (Prosopis leavigata) en productos de panificación. Compendio de Investigación Academia Journals Morelia 2018, 125-130.

Altamirano-Fortoul, R. (2018). Efecto de la adición de harina de vaina de mezquite (Prosopis laevigata) y diferentes aceites esenciales en productos derivados de cereales. Informe final de apoyo a la incorporación de nuevos PTC. PRODEP.

Arnero, C.M.A. (2015). La vaina de mezquite (Prosopis spp) en la alimentación del ganado. Tesis Licenciatura. Universidad Autónoma Agraria Antonio Narro Unidad Laguna División Regional de Ciencia Animal, México. 
Barba de la Rosa, A.P., Frias-Hernandez, J.T., Olalde-Portugal, V., \& González-Castañeda, J. (2006). Processing, nutritional evaluation and utilization of whole mesquite flour (Prosopis laevigata). Journal of Food Science, 71, 315-320.

Becker, R., Grosjean, 0.K. (1980). A compositional study of pods of two varieties of mesquite (Prosopis glandulosa, P. velutina). Journal of Agricultural and Food Chemistry, 28 22-25.

Avellaneda, R.E.E., y Cubas, Q.D.M. (2018). Formulación de panetón con sustitución parcial de harina de trigo (Triticum aestivum) por harina de algarroba (Prosopis alba). Tesis de Licenciatura. Universidad Nacional Pedro Ruiz Gallo, Perú.

Bigne, F., Puppo, M.C., \& Ferrero, C. (2016). Fibre enrichment of wheat flour with mesquite (Prosopis spp.): Effecton breadmaking performance and staling. LWT - Food Science and Technology, 65, 10081016.

Bigne, F., Puppo. M.C., \& Ferrero, C. (2018). Mesquite (Prosopis alba) flour as novel ingredient for obtaining a "panettone-like" bread. Applicability of part-baking technology. LWT- Food Science and Technology, 89, 666-673.

Cerezal, M. P., Acosta, B.E., Rojas, V.G., Romero, P.N., \& Arcos, Z.R. (2012). Desarrollo de una bebida de alto contenido proteico a partir de algarrobo, lupino y quinoa para la dieta de preescolares. Nutrición Hospitalaria, 27(1), 232-243.

Cervantes, M. (2002). Plantas de importancia económica en las zonas áridas y semiáridas de México. Primera edición. Ediciones UNAM. México.

Código Alimentario Argentino. (2010). Resolución Conjunta No 56/2010 y 538/2010- Modificación del Código Alimentario Argentino. Recuperado el 27 de junio de 2020: https://www.ecolex.org/fr/details/legislation/resolucion-conjunta-no-562010-y-5382010-modificaciondel-codigo-alimentario-argentino-lex-faoc097707/ 27/07/2020.

Correa, M.J., Salinas, M.V., Carbas, B., Ferrero, C., Brites, C., \& Puppo, M.C. (2017). Technological quality of dough and breads from commercial algarroba-wheat flour blends. Journal of Food Science and Technology, 54(7), 2104-2114.

Felker, P. (2011). Unpubl. Obsev.2011 en Felker, P., Takeoka, G., \& Dao, L. 2013. Pod Mesocarp Flour of North and South American Species of Leguminous Tree Prosopis (Mesquite): Composition and Food Applications. Food Reviews International, 29(1), 49-66.

Felker, P., Takeoka, G., \& Dao, L. (2013). Pod Mesocarp Flour of North and South American Species of Leguminous Tree Prosopis (Mesquite): Composition and Food Applications. Food Reviews International, 29(1), 49-66.

Gallegos-Infante, J.A., Rocha-Guzman, N.E., González, Laredo, R.F., \& García-Casas, M.A. (2013). Efecto del procesamiento térmico sobre la capacidad antioxidante de pinole a base de vainas de mezquite (Prosopis laevigata). CyTA - Journal of Food, 11(2), 162-170.

González-Barrón, U., Dijkshoorn, R., Maloncy, M., Finimundy, T., Calhelha, R.C., Pereira, C., Stojkovi'c, D., Sokovi'c, M., Ferreira C.F.R.I., Barros, L., \& Vasco, C. (2020). Nutritive and Bioactive Properties of Mesquite (Prosopis pallida) Flour and Its Technological Performance in Breadmaking. Foods. 1-25.

Grados, N., \& Cruz, G. (1996). New approaches to industrialization of algarrobo (Prosopis pallida) pods in Peru. En P. Felker y J. Moss (Eds), Prosopis: Semiarid Fuelwood and Forage Tree Building Consensus for the Disenfranchised. Texas A\&M University-Kingsville, Center for Semi-Arid Forest Resources, 3, $25-42$. 
Grados, N., Ruiz, W., Cruz, G., Díaz, C., \& Puicón, J. (2000). Productos industrializables de la algarroba peruana (Prosopis pallida): algarrobina y haría de algarroba. Multequina, 9(2), 119-132.

Guinnard, A. (1947). Tres aFios de esclavitud entre k. 'spatagones. Tercera edición. Buenos Aires, Espasa-Calpe Argentina, S. A (Argentina).

Meyer, D. (1984). Processing, utilization and economics of Mesquite pods as a raw material for the food industry. Tesis Doctoral. Diss. Swiss Federal Institute of Technology Zürich. Zurich.

NMX-F-007-(1982). Alimento para humanos harina de trigo. Normas mexicanas. Dirección general de Normas.

Ortiz, C. L.A. (2019). Caracterización fisicoquímica de la harina de vaina de mezquite (Prosopis laevigata) y evaluación de su efecto en productos de panificación. Tesis de Licenciatura. Universidad de la Cañada, México.

Palacios, R.A. (2006). Los mezquites Mexicanos: biodiversidad y distribución gráfica. Boletín de la Sociedad Argentina de Botánica, 41 (1-2), 99-121.

Pasiecznik, N., Fleker, O., Harris, P., Harsh, L., Cruz, G., Tewari, J., Cardoret, K., \& Maldonado, L. (2001). The prosopis juliflora-Prosopis pallida complex: A monography. HDRA, Coventry (Reino Unido).

Pérez, A., \& Corzo B.D.C. (2008). Análisis y selección de diferentes métodos para eliminar las saponinas en dos variedades de Chenopodium quinoa Willd. Jardín Botánico, 153-162.

Prokopiuk, D., Cruz, G., Grados, N., Garro, O., \& Chiralt, A. (2000). Estudio comparativo entre frutos de Prosopis alba y Prosopi spallida. Multequina, 9, 35-45.

Prokopiuk, D.B. (2004). Sucedáneo del café a partir de algarroba (Prosopis alba Griseb). Tesis de Doctorado. Universidad Politécnica de Valencia, España.

Rodríguez, S.E.N, Rojo, M.G.E, Ramírez, V.B., Martínez, R.R., Cong. H M.C., Medina. T.S.M., Piña, R.H.H. (2014). Análisis técnico del árbol de mezquite (Prosopis leavigata humb, \& Bonpl. Ex Wild.) en México. Ra Ximhai, 10(3), 173-193.

Ruíz, T.D.R. (2011). Uso potencial de la vaina de mezquite para la alimentación de animales domésticos del Altiplano potosino. Tesis de Maestría, Universidad autónoma de san Luis Potosí, México.

Sciammaro, L.P., Ferrero, C., Puppo, M.C. (2016). Chemical and nutritional properties of different fractions of Prosopis alba pods and seeds. Journal of Food Measurement and Characterization, 10(1), 103-112.

Smith, C. E. (1967). Plant remains. En: The prehistory of the Tehuacán Valley. Volume one Byers, D. S. (Ed.). Environment and subsistence. Estados Unidos de América. University of Texas Press, Ltd, (London).

Trejo, E.J.L. (2010). Establecimiento de un cultivo de células en suspensión de P. leavigata Humboldt et bonpland Ex Willd. M.C. Johnst. Para la producción de goma de mezquite. Tesis de Doctorado. Universidad Autónoma Metropolitana - Iztapalapa, México.

Valenzuela, N.L.M., Ríos, S.J.C., Barrientos, A.K.R., Muro, G.P, Sánchez, S.J., \& Briceño, C.E.A. (2015). Estructura y composición florística en dos comunidades de mezquite (Prosopis leavigata (Humb. \& Bonpl. Ex Willd) M.C. Johnst) en Durango, México. Interciencia, 4, 465-472. 